\title{
АНАЛИЗ СВЯЗИ ПОЛИМОРФНЫХ ВАРИАНТОВ ГЕНОВ IL4, IL10, IL13 С РАЗВИТИЕМ АТОПИЧЕСКОЙ БРОНХИАЛЬНОЙ АСТМЫ И РЕМИССИЕЙ
}

\author{
Ю. В. Жорина ${ }^{1}$, О. С. Абрамовских 1 Г. Л. Игнатова', О. Г. Площанская²
}

Южно-Уральский государственный медицинский университет, Челябинск, Россия

2 ООО «ДНК Клиника», Челябинск, Россия

\begin{abstract}
Бронхиальная астма (БА) является многофакторным заболеванием, в основе которого лежит хроническое воспаление. Атопический фенотип предполагает наличие у пациентов сходных молекулярных механизмов патогенеза. Целью работы было провести анализ ассоциации полиморфных локусов генов IL4 (rs2243250; C-5897), IL10 (rs1800896; G-1082A; rs1800872; C-592A), IL13 (rs20541; Arg130Gln) с развитием атопической БA и ремиссией. С помощью аллель-специфичной полимеразной цепной реакции (ПЦР) проведено исследование полиморфных локусов генов больных БА $(n=53)$ и группы сравнения ( $n=30)$, смешанной городской выборки, проживающих на Южном Урале. Анализ ассоциации полиморфных вариантов генов интерлейкинов с развитием БА показал, что генотип AA IL10 (rs1800872) встречается чаще в группе сравнения (23,3\%), чем в группе атопической БА (5,7\%) (ОШ = 0,197; 95\% ДИ [0,047-0,832]; $p=0,031)$. Для остальных исследованных полиморфных локусов генов интерлейкинов отличий в частотах генотипов между больными атопической БА и группой сравнения не обнаружено. Не удалось показать влияние изученных полиморфных локусов на развитие ремиссии заболевания.
\end{abstract}

Ключевые слова: бронхиальная астма у взрослых, атопия, ремиссия, полиморфизм генов, цитокинь

Информация о вкладе авторов: Ю. В. Жорина - общая идея и методология исследования, сбор, обработка и интерпретация данных, статистический анализ, написание и оформление статьи; О. С. Абрамовских - методика и курирование исследования, анализ и интерпретация данных, написание и оформление статьи; Г. Л. Игнатова - анализ клинической части данных, курирование исследования, интерпретация данных, написание статьи; О. Г. Площанская — сбор данных, осуществление лабораторного этапа обследования, интерпретация данных, написание статьи.

Соблюдение этических стандартов: исследование одобрено этическим комитетом ФГБОУ ВО «ЮУГМУ Минздрава» (протокол № 10 от 17 ноября 2016 г.). Все участники подписали добровольное информированное согласие на участие в исследовании.

$\bigotimes$ Для корреспонденции: Юлия Владимировна Жорина

ул. Воровского, д. 64, г. Челябинск, 454092; juliamart24@mail.ru

Статья получена: 25.09.2019 Статья принята к печати: 11.10.2019 Опубликована онлайн: 21.10.2019

DOI: $10.24075 /$ vrgmu.2019.067

\section{ANALYSIS OF ASSOCIATIONS OF POLYMORPHISMS IN THE GENES CODING FOR L4, IL10, IL13 WITH THE DEVELOPMENT OF ATOPIC BRONCHIAL ASTHMA AND ITS REMISSION}

Zhorina YuV ${ }^{1 凶}$, Abramovskikh OS ${ }^{1}$, Ignatova $\mathrm{GL}^{1}$, Ploshchanskay $\mathrm{OG}^{2}$

South Ural State Medical University, Chelyabinsk, Russia

2 DNA Clinic LLC, Chelyabinsk, Russia

Bronchial asthma is a multifactorial disease underpinned by chronic inflammation. The atopic phenotype of BA implies the presence of similar molecular mechanisms of pathogenesis between the patients. The aim of this study was to analyze the associations between the development of atopic BA/its remission and the following polymorphisms of interleukin genes: IL4 (rs2243250; C-5897), IL10 (rs1800896; G-1082A; rs1800872; C-592A), and IL13 (rs20541; Arg130Gln). Using allelespecific polymerase chain reaction (PCR), we studied the listed SNPs in the mixed urban sample of patients with BA $(n=53)$ and the controls $(n=30)$ residing in South Ural. The analysis revealed that genotype AA of IL10 (rs 1800872) occurred more frequently in the control group (23.3\%) than in the patients with atopic BA $(5.7 \%)(\mathrm{OR}=0.197 ; 95 \% \mathrm{Cl}[0.047-0.832] ; p=0.031)$. No differences in genotype frequencies were observed between the patients with atopic BA and the controls for other studied polymorphisms. Our study failed to demonstrate the association of the listed polymorphisms and BA remission.

Keywords: bronchial asthma in adults, atopy, remission, gene polymorphism, cytokines

Author contribution: Zhorina YuV — conceived and planned the study, collected, processed and interpreted the data, performed statistical analysis, participated in writing the manuscript; Abramovskikh OS - proposed the method and supervised the study, analyzed and interpreted the data, participated in writing the manuscript; Ignatova GL — analyzed the clinical data, supervised the study, interpreted the data, participated in writing the manuscript; Ploshchanskay OG collected the data, conducted laboratory tests, interpreted the data and participated in writing the manuscript.

Compliance with ethical standards: the study was approved by the Ethics Committee of South Ural State Medical University (Protocol № 10 dated November 17, 2016). The patients gave informed consent to participate in the study.

$\triangle$ Correspondence should be addressed: Yulia Yu. Zhorina Vorovskogo, 64, Chelyabinsk, 454092; juliamart24@mail.ru

Received: 25.09.2019 Accepted: 11.10.2019 Published online: 21.10.2019

DOI: $10.24075 /$ brsmu.2019.067

Бронхиальная астма (БА) - сложное заболевание, в патогенезе которого случайным образом сочетаются как аллергические, так и неаллергические факторы. Известно большое разнообразие фенотипов БА. По данным эпидемиологических исследований, частота атопического фенотипа БА у взрослых преобладает и колеблется от 40 до 80\% в общей структуре заболевания. В российских исследованиях атопический вариант БА у взрослых диагностировали в 68-78\% случаев [1].
Генетическая предрасположенность вносит значительный вклад в развитие астмы. Так, семейная агрегация астмы была продемонстрирована еще в первой половине прошлого столетия. Исследования близнецов, проведенные во второй половине XX в., показали широкий диапазон в оценках наследственности астмы (36-95\%) [2]. В последние несколько лет особое внимание было уделено проведению генетических исследований БА с очень большими размерами выборки без учета конкретного 
фенотипа заболевания [3]. Анализ генов-кандидатов в фенотипически гомогенных выборках позволяет выделять группы со сходной молекулярно-генетической основой заболевания. Однородные небольшого размера выборки могут быть достаточными для выявления генетического эффекта у исследуемого гена [4].

Атопические расстройства считают иммунным ответом (гиперчувствительность типа I), связанным и/или опосредованным молекулами иммуноглобулина $\mathrm{E}$ к антигенам окружающей среды. Реакции, связанные с атопическими расстройствами, делят на несколько основных категорий, одни из которых участвуют в функции эпидермального барьера, другие - в регуляции врожденного и адаптивного иммунного ответа, включая сенсибилизацию IgE [5].

В перечне генов, положительные ассоциации которых с аллергией и астмой доказаны различными исследователями, присутствовали гены-кандидаты, кодирующие цитокины IL4, IL10 и IL13, участвующие в регуляции персистирующего аллергического воспаления [6]. Ассоциация полиморфизмов генов перечисленных цитокинов с бронхиальной астмой определена и отечественными авторами $[7,8]$.

Большинство исследований по генетике БА посвящено определению предрасположенности $\mathrm{k}$ развитию заболевания [9]. Работ по изучению течения и прогрессирования заболевания недостаточно. Более того, имеются данные, что известные в настоящее время генетические факторы риска развития заболевания пока не позволяют точно прогнозировать возникновение и течение БА [10].

По данным зарубежных авторов, частота ремиссии астмы составляет от 5\% у пациентов с поздно начавшейся астмой [11] до 65\% у детей и подростков [12]. По нашим данным, частота ремиссии атопической БА у взрослых в Челябинске составляет 22,7\%. Положительная связь с наступлением ремиссии отмечается у пациентов с нормальным индексом массы тела, проведением аллергенспецисичной терапии и элиминационных мероприятий. Другие клинико-анамнестические факторы (пол, возраст начала появления симптомов, длительность заболевания, отягощенный семейный анамнез, сочетание с сезонным или круглогодичным ринитом, отношение к курению) не выявили существенных различий в группах пациентов с ремиссией и без ремиссии заболевания [13].

Целью исследования было проанализировать ассоциации полиморфных локусов генов IL4 (rs2243250; C-589T), IL10 (rs1800896; G-1082A; rs1800872; C-592A), IL13 (rs20541; Arg130G/n) с развитием атопической БА и ремиссией в смешанной городской выборке жителей г. Челябинска (Южный Урал).

\section{ПАЦИЕНТЫ И МЕТОДЫ}

Проведено телефонное анкетирование 181 пациента с атопической БА, наблюдавшихся в период с 1992 по 2018 г. на базе аллергологического кабинета МБУЗ «Городская клиническая поликлиника № 7» г. Челябинска. Диагноз заболевания устанавливал (подтверждал) врач аллерголог-иммунолог на основании данных клинического, лабораторного, инструментального методов исследования и кожных аллергических проб в соответствии с критериями программных документов по диагностике, лечению и профилактике бронхиальной астмы [14]. Медиана продолжительности наблюдения составила 8 лет [5; 15 лет].
Критерии включения пациентов в исследование: пациенты обоих полов в возрасте 18-70 лет; наличие диагноза атопической БА легкой или средней степени тяжести; подтвержденная сенсибилизация к неинфекционным аллергенам; период наблюдения не менее 3 лет; согласие на участие в исследовании. Критерии исключения: сочетание БА и хронической обструктивной болезни легких; силикоз, туберкулез, саркоидоз, бронхоэктатическая болезнь, операции на легких.

Комплексное обследование прошли 53 человека в возрасте 23-70 лет: клиническое (детализация жалоб и симптомов по основному и сопутствующим заболеваниям, сбор аллергологического анамнеза, оценка физикального статуса пациента, определение уровня контроля заболевания - балльная шкала симптомов, АСТ-тест); исследование полиморфизмов генов интерлейкинов методом аллель-специфичной полимеразной цепной реакции, ПЦР); инструментальное (спирометрия с пробой на обратимость бронхиальной обструкции).

Молекулярно-генетическое исследование проводили на базе лаборатории «ООО ДНК» (г. Челябинск). Геномную ДНК больных и участников группы сравнения выделяли из лейкоцитов цельной крови с помощью реагента «ДНКэкспресс-кровь» (ДНК-технология; Россия). Однонуклеотидные полиморфизмы (ОНП) генов IL4 (rs2243250; C-589T), IL10 (rs1800896; G-1082A; rs1800872; C-592 A), IL13 (rs20541; Arg130G/n) идентифицировали с помощью тест-системы «SNP-экспресс» (НПФ Литех; Россия) методом аллельспецисичной ПЦР.

Спирометрические критерии нормальной функции легких: отсутствие бронхиальной обструкции, определяемой как отношение объема форсированного выдоха за 1 с (ОФВ1) к форсированной жизненной емкости легких (ФЖЕЛ) менее 0,7 до применения бронхолитика. Бронходилатационный тест считали положительным, если прирост ОФВ1 составлял $12 \%$ и более после ингаляции четырех доз сальбутамола и абсолютный прирост был больше 200 мл [15].

В литературе предложены определения ремиссии астмы, основанные на ее продолжительности от 1 до 6 лет. Кроме того, существуют значительные различия в определении ремиссии в некоторых исследованиях, основанных на разрешении клинических симптомов, в то время как в других необходима объективная оценка нормальной функции легких [16].

Поскольку нет единого мнения относительно определения этого периода течения БА, клиническую ремиссию определяли как отсутствие в течение года симптомов (приступов кашля, одьшки или удушья, свистящего дыхания), базисной терапии и применения $\beta 2$-агонистов короткого действия при нормальной функции легких и отрицательной пробе при спирометрии. На основании критериев включения и исключения были сформированы следующие группы: пациенты с ремиссией атопической БА - 17 человек (14 мужчин и 3 женщины), пациенты без ремиссии атопической БА - 36 человек (14 мужчин и 22 женщины). Группу сравнения составили 30 человек в возрасте 23-73 лет (11 мужчин и 19 женщин), прошедших анкетирование на отсутствие респираторных жалоб, без аллергических заболеваний, с неотягощенной наследственностью по аллергическим заболеваниям.

Данные обрабатывали с помощью компьютерной программы SPSS Statistics 17.0.1 (SPSS Inc; США). Анализ вариационных рядов проводили методами описательной статистики. Качественные переменные описывали абсолютными и относительными частотами. Анализ 
вариационных рядов проводили методами описательной статистики: для количественных переменных определяли медиану (Ме) и интерквартильный интервал [IQR, 25\% : 75\%]. Анализ вида распределения количественных данных проводили с использованием критерия Шапиро-Уилка. Для сравнения двух выборочных средних в независимых группах использовали критерий Манна-Уитни, при уровне значимости р менее 0,05.

Рассчитывали частоты аллелей и генотипов изученных полиморфных локусов генов-кандидатов, соответствие распределения частот генотипов равновесию ХардиВайнберга ( $\chi^{2}$ при уровне значимости $p$ менее 0,05), при попарном сравнении частот аллелей и генотипов в группах больных и контроля использовали двусторонний точный метод Фишера. Для анализа ассоциации рассчитывали показатель отношения шансов (ОШ) и 95\%-й доверительный интервал (ДИ).

\section{РЕЗУЛЬТАТЫ ИССЛЕДОВАНИЯ}

Пациенты с атопической БА $(n=53)$ имели следующие клинические характеристики: наличие полисенсибилизации (к бытовым, эпидермальным, растительным аллергенам) у $68 \%(n=36)$; наследственная отягощенность - у $47 \%$ ( $\mathrm{n}=25) ;$ начало заболевания до 18 лет - у 42\% ( $n=22)$; сочетание с аллергическим ринитом - у 78\% ( $n=41)$; тяжесть заболевания (на момент постановки диагноза) легкая - у $72 \%(n=38)$, средняя - у 28\% $(n=15)$. В группе пациентов с ремиссией атопической БА определена нормальная функция легких и не обнаружено статистически значимых различий в результатах бронходилатационного теста относительно группы сравнения (табл. 1). У пациентов без ремиссии заболевания выявлены положительные результаты бронходилатационного теста, меньшие значения ОФВ1 \% и ОФВ/ФЖКЕЛ \% пО отношению к группе сравнения.

Частоты генотипов рассчитаны для общей группы больных атопической БА по отношению к группе сравнения, а также для групп с ремиссией и без ремиссии заболевания. Для всех исследованных локусов определено неравновесие по сцеплению в группе сравнения и соответствие соотношению Харди-Вайнберга в группе пациентов с атопической БА.

Анализ ассоциации полиморфных локусов генов интерлейкинов с развитием БА (табл. 2) показал статистически значимое различие по частоте генотипов IL10 (rs1800872): генотип AA чаще встречается в группе сравнения (23,3\%), чем в группе атопической БА (5,7\%) $($ ОШ $=0,197 ; 95 \%$ ДИ $[0,047-0,832] ; p=0,031)$, и, вероятно, имеет протективное значение. Для остальных исследованных ОНП различий в частотах генотипов между больными атопической БА и группой сравнения не обнаружено.

Межгрупповой сравнительный анализ показал различие по частоте генотипов IL10 (rs 1800872) у пациентов без ремиссии атопической БА по отношению к группе сравнения: частота генотипа AА составила 2,8\% против 23,3\% (ОШ = 0,094; 95\% ДИ [0,011-0,814]; $p=0,019)$. При совокупной оценке данных клинического и молекулярногенетического обследований не выявлено статистически значимых ассоциаций с развитием ремиссии (табл. 3).

Таблица 1. Показатели спирометрии у пациентов в периоде ремиссии атопической бронхиальной астмы, без ремиссии и группы сравнения

\begin{tabular}{|c|c|c|c|c|c|}
\hline Показатель & $\begin{array}{c}\text { Пациенты } \\
\text { с ремиссией БА, } \\
n=17 \text { (группа 1) }\end{array}$ & $\begin{array}{c}\text { Пациенты с БА без ремиссии } \\
\text { (контролируемое, частично контролируемое и } \\
\text { неконтролируемое течение) (группа 2), } n=36\end{array}$ & $\begin{array}{c}\text { Группа сравнения } \\
\text { (группа 3), } n=30\end{array}$ & $\begin{array}{c}\text { p-величина } \\
\text { (группы 1-3) }\end{array}$ & $\begin{array}{c}\text { p-величина } \\
\text { (группы 1-2) }\end{array}$ \\
\hline OФB1 \%, Me [Q1; Q3] & $99[89,5 ; 107,8]$ & $84[74 ; 97]$ & $104[95,5 ; 110]$ & 0,4 & 0,001 \\
\hline $\begin{array}{l}\text { Прирост ОФВ1 в мл после } \\
\text { пробы с сальбутамолом } \\
\text { (400 мкг), Ме [Q1; Q3] }\end{array}$ & $155[0 ; 247,5]$ & $240[107,5 ; 445]$ & $167,5[82,25 ; 228,75]$ & 0,72 & 0,013 \\
\hline ОФВ1/ФЖЕЛ \%, Ме [Q1; Q3] & $81,5[76,3 ; 88,5]$ & $74[67 ; 79,75]$ & $83[80,5 ; 85,5]$ & 0,69 & 0,001 \\
\hline
\end{tabular}

Таблица 2. Распределение частот генотипов полиморфных локусов генов интерлейкинов у больных атопической БА и в группе сравнения

\begin{tabular}{|c|c|c|c|c|}
\hline Генотип & $\begin{array}{c}\text { Пациенты с атопической БА } \\
(n=53), \%(n)\end{array}$ & $\begin{array}{l}\text { Группа сравнения } \\
\qquad(n=30), \%(n)\end{array}$ & ОШ (95\% ди) & $p$-величина \\
\hline \multicolumn{5}{|c|}{ IL4 (rs2243250) } \\
\hline$C C$ & $52,8(28)$ & $53,3(16)$ & $0,98(0,39-2,4)$ & 1,000 \\
\hline$\overline{C T}$ & $43,3(23)$ & $46,6(14)$ & $0,876(0,35-2,15)$ & 0,821 \\
\hline$\pi$ & $3,8(2)$ & $0(0)$ & $0,63(0,53-0,74)$ & 0,533 \\
\hline \multicolumn{5}{|c|}{ IL10 (rs1800896) } \\
\hline$G G$ & $37,7(20)$ & $43,3(13)$ & $0,79(0,31-1,97)$ & 0,647 \\
\hline$G A$ & $45,3(24)$ & $30(9)$ & $1,93(0,74-4,93)$ & 0,243 \\
\hline$A A$ & 17 (9) & 26,6 (8) & $0,56(0,19-1,65)$ & 0,397 \\
\hline \multicolumn{5}{|c|}{ IL10 (rs1800872) } \\
\hline$C C$ & $56,6(30)$ & $46,6(14)$ & $1,49(0,60-3,66)$ & 0,493 \\
\hline$C A$ & $37,7(20)$ & 30 (9) & $1,41(0,54-3,68)$ & 0,632 \\
\hline$A A$ & $5,7(3)$ & $23,3(7)$ & $0,197(0,047-, 832)$ & 0,031 \\
\hline \multicolumn{5}{|c|}{ IL13 (rs20541) } \\
\hline$G G$ & $55(29)$ & $56,6(17)$ & $0,924(0,37-2,27)$ & 1,000 \\
\hline$G A$ & $34(18)$ & $30(9)$ & $1,2(0,45-3,15)$ & 0,810 \\
\hline$A A$ & $11(6)$ & $13,3(4)$ & $0,83(0,21-3,21)$ & 1,000 \\
\hline
\end{tabular}


Таблица 3. Частота генотипов полиморфных локусов генов интерлейкинов у пациентов с атопической БА в зависимости от клинического течения

\begin{tabular}{|c|c|c|c|c|c|}
\hline Генотип & $\begin{array}{c}\text { Пациенты с ремиссией БА } \\
\text { (группа 1) } n=17, \% \text { (n) }\end{array}$ & $\begin{array}{c}\text { Пациенты с БА без ремиссии } \\
\text { (группа 2) } n=36, \% \text { ( } n)\end{array}$ & $\begin{array}{c}\text { Группа сравнения } \\
\text { (группа 3) } n=30, \%(n)\end{array}$ & $\begin{array}{c}\text { Группы сравнения, ОШ } \\
\text { (95\%ДИ) }\end{array}$ & $p$-величина \\
\hline \multicolumn{6}{|c|}{ IL4 (rs2243250) } \\
\hline$C C$ & $52,9(9)$ & $52,7(19)$ & $53,3(16)$ & $\begin{array}{l}1-3=1,01(0,30-3,34) \\
2-3=0,97(0,37-2,58)\end{array}$ & $\begin{array}{l}1-3=1,000 \\
2-3=1,000\end{array}$ \\
\hline$C T$ & $47,1(8)$ & $41,7(15)$ & $46,6(14)$ & $\begin{array}{l}1-3=0,98(0,29-3,24) \\
2-3=0,81(0,31-2,16)\end{array}$ & $\begin{array}{l}1-3=1,000 \\
2-3=0,804\end{array}$ \\
\hline$\pi T$ & $0(0)$ & $5,6(2)$ & $0(0)$ & $\begin{array}{l}1-3=- \\
2-3=0,53(0,42-0,7)\end{array}$ & $\begin{array}{l}1-3=- \\
2-3=0,497\end{array}$ \\
\hline \multicolumn{6}{|c|}{ IL10 (rs1800896) } \\
\hline$G G$ & $47,1(8)$ & 33,3 (12) & 43,3 (13) & $\begin{array}{l}1-3=0,86(0,26-2,84) \\
2-3=0,65(0,24-1,77)\end{array}$ & $\begin{array}{l}1-3=1,000 \\
2-3=0,452\end{array}$ \\
\hline$G A$ & $35,3(6)$ & $50(18)$ & $30(9)$ & $\begin{array}{l}1-3=0,78(0,22-2,78) \\
2-3=2,3(0,84-6,45)\end{array}$ & $\begin{array}{l}1-3=0,753 \\
2-3=0,133\end{array}$ \\
\hline$A A$ & $17,6(3)$ & $16,7(6)$ & $26,6(8)$ & $\begin{array}{l}1-3=1,69(0,38-7,5) \\
2-3=0,55(0,16-1,8)\end{array}$ & $\begin{array}{l}1-3=0,722 \\
2-3=0,375\end{array}$ \\
\hline \multicolumn{6}{|c|}{ IL10 (rs1800872) } \\
\hline$C C$ & $47,1(8)$ & $61,1(22)$ & 46,6 (14) & $\begin{array}{l}1-3=0,98(0,29-3,24) \\
2-3=1,79(0,67-4,79)\end{array}$ & $\begin{array}{l}1-3=1,000 \\
2-3=0,322\end{array}$ \\
\hline$C A$ & $41,1(7)$ & $36,1(13)$ & $26,6(8)$ & $\begin{array}{l}1-3=0,61(0,17-2,12) \\
2-3=1,31(0,46-3,71)\end{array}$ & $\begin{array}{l}1-3=0,528 \\
2-3=0,794\end{array}$ \\
\hline$A A$ & $11,7(2)$ & $2,8(1)$ & 23,3 (7) & $\begin{array}{l}1-3=2,28(0,41-12,5) \\
2-3=0,094(0,011-0,814)\end{array}$ & $\begin{array}{l}1-3=0,455 \\
2-3=0,019\end{array}$ \\
\hline \multicolumn{6}{|c|}{ IL13 Arg130 Gln (rs20541) } \\
\hline$G G$ & $52,9(9)$ & $55,6(20)$ & $56,6(17)$ & $\begin{array}{l}1-3=1,16(0,35-3,8) \\
2-3=0,95(0,36-2,53)\end{array}$ & $\begin{array}{l}1-3=1,000 \\
2-3=1,000\end{array}$ \\
\hline$G A$ & $29,4(5)$ & $36,1(13)$ & $30(9)$ & $\begin{array}{l}1-3=1,02(0,28-3,28) \\
2-3=1,31(0,47-3,7)\end{array}$ & $\begin{array}{l}1-3=1,000 \\
2-3=0,794\end{array}$ \\
\hline$A A$ & $17,7(3)$ & $8,3(3)$ & $13,3(4)$ & $\begin{array}{l}1-3=0,71(0,14-3,6) \\
2-3=0,59(0,12-2,87)\end{array}$ & $\begin{array}{l}1-3=0,692 \\
2-3=0,693\end{array}$ \\
\hline
\end{tabular}

\section{ОБСУЖДЕНИЕ РЕЗУЛЬТАТОВ}

Результаты предыдущих исследований полиморфного локуса C-592A гена IL10 противоречивы, так в одних исследованиях показано, что нет связи с предрасположенностью к астме [17], в других выявлены значительные корреляции [18, 19]. Ранее проведенные метаанализы показали ассоциацию полиморфизма C-589T в гене IL4 с риском развития БА у индивидов европейского происхождения [20], полиморфизма Arg130GIn в гене IL13 - с увеличением риска развития БА у детей и взрослых [21-23]. По данным литературы, полиморфный вариант G-1082A гена IL10 предрасполагает к развитию астмы [24].

Предполагается, что фракторы, способствующие развитию заболевания, могут отличаться от тех, которые влияют на его прогрессирование [25]. Возможно, что наличие изучаемых ОНП генов интерлейкинов не связано с прогнозом течения заболевания, для выяснения этого необходимо исследование на больших группах.
ВЫВОДЫ

Впервые получены данные о распределении генотипов полиморфных локусов C-589T в гене IL4, G-1082A и C-592A в гене IL10, Arg130G/n в гене IL13 при атопической БА в смешанной городской выборке жителей Южного Урала. Учитывая, небольшое число пациентов, участвующих в исследовании, результаты следует интерпретировать с осторожностью. В настоящее время изучены многие генетические аспекты БА, которые вносят вклад в понимание патогенеза этого многосакторного заболевания. Дальнейшие исследования в этом направлении необходимы, в том числе с целью большей адаптации генетических методов диагностики в реальной клинической практике. Исследование полиморфных локусов генов интерлейкинов может стать дополнительным инструментом для определения прогноза заболевания при консультировании пациентов, что будет способствовать повышению их приверженности к лечению.

\section{Литература}

1. Ненашева Н. М. Атопическая бронхиальная астма: роль аллерген-специфической иммунотерапии. Российский аллергологический журнал. 2015; ( 6): 54-67.

2. Mathias RA. Introduction to genetics and genomics in asthma: genetics of asthma. Adv Exp Med Biol. 2014; (795): 125-55. DOI: 10.1007/978-1-4614-8603-9_9.

3. Baye TM, Martin LJ, Khurana Hershey GK. Application of genetic/ genomic approaches to allergic disorders. J Allergy Clin Immunol. 2010; 126 (3): 425-36. DOI: 10.1016/j.jaci.2010.05.025.

4. Gupta J, Johansson E, Bernstein JA, Chakraborty R, Khurana Hershey GK, Rothenberg ME, et al. Resolving the etiology of atopic disorders by genetic analysis of racial ancestry. J Allergy Clin Immunol. 2016; 138 (3): 676-99. DOI: 10.1016/j.jaci.2016.02.045.

5. Halapi E, Hakonarson $H$. Recent development in genomic and proteomic research for asthma. Curr Opin Pulm Med. 2004; 10 (1): 22-30. DOI: 10.1097/00063198-200401000-00005.

6. Ober C, Hoffja S. Asthma genetics 2006: the long and winding road to gene discovery. Genes Immun. 2006; 7 (2): 95-100. 
DOI:10.1038/sj.gene.6364284.

7. Смольникова М. В., Фрейдин М. Б., Смирнова С. В. Гены цитокинов как генетические маркеры атопической бронхиальной астмы с контролируемым и неконтролируемым течением. Медицинская иммунология. 2017; 19 (5): 605-14. DOI: 10.15789/1563-0625-2017-5-605-614.

8. Карунас А. С., Федорова Ю. Ю., Рамазанова Н. Н., Галимова Е. С., Гималова Г. Ф., Гурьева Л. Л. и др. Исследование роли полиморфных вариантов генов цитокинов в развитии бронхиальной астмы в Республике Башкортостан. Пульмонология. 2012; (5): 37-40.

9. Marenholz I, Esparza-Gordillo J, Rüschendorf F, Bauerfeind A Strachan DP, Spycher BD, et al. Meta-analysis identifies seven susceptibility loci involved in the atopic march. Nat Commun. 2015; (6): 8804. DOI: 10.1038/ncomms9804.

10. Belsky DW, Sears MR, Hancox RJ, Harrington H, Houts R, Moffitt TE, et al. Polygenic risk and the development and course of asthma: Evidence from a 4-decade longitudinal study. Lancet Respir Med. 2013; 1 (6): 453-61. DOI: 10.1016/S2213-2600(13)70101-2.

11. Tiomisto LE, Ilmarinen P, Kankaanranta H. Prognosis of newonset asthma diagnosed in adult age. Respir Med. 2015; 109 (8): 944-54. DOI: 10.1016/j.rmed.2015.05.001

12. Javed $A$, Yoo $K H$, Agarwal $K$, Jacobson RM, Li X, Juhn $Y J$, et al. Characteristics of children with asthma who achieved remission of asthma. J Asthma. 2013; 50 (5): 472-9. DOI: 10.3109/02770903.2013.787625.

13. ИгнатоваГ. Л., Жорина Ю. В., Абрамовских О. С., Жеребцова И. А. Особенности течения и частота ремиссии атопической бронхиальной астмы у взрослых пациентов в Челябинске. Пульмонология. 2019; 29 (3): 263-8. DOI: 10.18093/08690189-2019-29-3-263-268.

14. Global Initiative for asthma - NHLBI/WHO Workshop Report/ National Heart Lung Blood Institute Updated 2016. https:// ginasthma.org/ (дата обращения: 19.09.2018).

15. Чучалин А. Г., Айсанов З. Р., Чикина С. Ю., Черняк А. В., Калманова Е. Н. Федеральные клинические рекомендации Российского респираторного общества по использованию метода спирометрии. Пульмонология. 2014; (6): 11-23.

\section{References}

1. Nenasheva NM. Atopicheskaya bronhial'naya astma: rol' allergenspecificheskoj immunoterapii. Rossijskij allergologicheskij zhurnal. 2015; (6): 54-67. Russian.

2. Mathias RA. Introduction to genetics and genomics in asthma: genetics of asthma. Adv Exp Med Biol. 2014; (795): 125-55. DOI: 10.1007/978-1-4614-8603-9 9.

3. Baye TM, Martin LJ, Khurana Hershey GK. Application of genetic/ genomic approaches to allergic disorders. J Allergy Clin Immunol. 2010; 126 (3): 425-36. DOI: 10.1016/j.jaci.2010.05.025.

4. Gupta J, Johansson E, Bernstein JA, Chakraborty R, Khurana Hershey GK, Rothenberg ME, et al. Resolving the etiology of atopic disorders by genetic analysis of racial ancestry. J Allergy Clin Immunol. 2016; 138 (3): 676-99. DOI: 10.1016/j.jaci.2016.02.045.

5. Halapi $\mathrm{E}$, Hakonarson $\mathrm{H}$. Recent development in genomic and proteomic research for asthma. Curr Opin Pulm Med. 2004; 10 (1): 22-30. DOI: 10.1097/00063198-200401000-00005.

6. Ober C, Hoffja S. Asthma genetics 2006: the long and winding road to gene discovery. Genes Immun. 2006; 7 (2): 95-100. DOI:10.1038/sj.gene.6364284.

7. Smolnikova MV, Freidin MB, Smirnova SV. Cytokine genes as genetic markers of controlled and uncontrolled atopic bronchial asthma Medical Immunology (in Russia)/Meditsinskaya Immunologiya. 2017; 19 (5): 605-14. DOl: 10.15789/1563-0625-2017-5-605-614. Russian.

8. Karunas AS, Fedorova YY, Ramazanova NN, Galimova ES, Gimalova GF, Guryeva $L$, et al. Evaluation of a role of cytokine gene polymorphisms in development of bronchial asthma in the Republic of Bashkortostan. Russian Pulmonology. 2012; (5): 37-40. Russian.

9. Marenholz I, Esparza-Gordillo J, Rüschendorf F, Bauerfeind A, Strachan DP, Spycher BD, et al. Meta-analysis identifies seven susceptibility loci involved in the atopic march. Nat Commun. 2015; (6): 8804. DOI: 10.1038/ncomms9804.
16. Koh $\mathrm{YY}$, Kang H, Nah KM, Kim CK. Absence of association of peripheral blood eosinophilia or increased eosinophil cationic protein with bronchial hyperresponsiveness during asthma remission. Ann Allergy Asthma Immunol. 2003; 91 (3): 297-302. DOI: 10.1016/S1081-1206(10)63533-8.

17. Karjalainen J, Hulkkonen J, Nieminen MM, Huhtala H, Aromaa A, Klaukka T, et al. Interleukin-10 gene promoter region polymorphism is associated with eosinophil count and circulating immunoglobulin E in adult asthma. Clin Exp Allergy. 2003; 33 (1): 78-83. DOI: 10.1046/j.1365-2222.2003.01577.x

18. Huang ZY, Cheng BJ, Wan Y, Zhou C. Meta-analysis of the IL10 promoter polymorphisms and pediatric asthma susceptibility. Genet Mol Res. 2016; 15 (2): gmr.15028320 DOI: 10.4238/ gmr.15028320.

19. Nie W, Fang Z, Li B, Xiu QY. Interleukin-10 promoter polymorphisms and asthma risk: a meta-analysis. Cytokine. 2012; 60 (3): 849-55. DOI: 10.1016/j.cyto.2012.08.023.

20. Tang L, Lin HG, Chen BF. Association of IL4 promoter polymorphisms with asthma: a meta-analysis. Genet Mol Res. 2014; 13 (1): 1383-94.

21. Heinzmann $A$, Mao $X-Q$, Akaiwa $M$, Kreomer RT, Gao PS, Ohshima K, et al. Genetic variants of IL13 signalling and human asthma and atopy. Human Molecular Genetics. 2000; 9 (4): 54959. DOI: $10.1093 / \mathrm{hmg} / 9.4 .549$.

22. Liu Z, Li P, Wang J, Fan Q, Yan P, Zhang X, et al. A meta-analysis of IL13 polymorphisms and pediatric asthma risk. Med Sci Monit. 2014; (20): 2617-23. DOI: 10.12659/MSM.891017.

23. Mei Q, Qu J. Interleukin-13 +2044 G/A and $+1923 \mathrm{C} / \mathrm{T}$ polymorphisms are associated with asthma susceptibility in Asians: A meta-analysis. Medicine (Baltimore). 2017; 96 (51): e9203. DOI: 10.1097/MD.0000000000009203.

24. Zheng XY, Guan WJ, Mao C, Chen HF, Ding H, Zheng JP, et al. Interleukin-10 promoter 1082/2819/2592 polymorphisms are associated with asthma susceptibility in Asians and atopic asthma: a meta-analysis. Lung. 2014; 192 (1): 65-73.

25. Guerra S. Clinical remission of asthma: what lies beyond? Thorax. 2005; 60 (1): 5-6. DOI: 10.1136/thx.2004.033480.

10. Belsky DW, Sears MR, Hancox RJ, Harrington H, Houts R, Moffitt TE, et al. Polygenic risk and the development and course of asthma: Evidence from a 4-decade longitudinal study. Lancet Respir Med. 2013; 1 (6): 453-61. DOI: 10.1016/S2213-2600(13)70101-2.

11. Tiomisto LE, IImarinen P, Kankaanranta H. Prognosis of newonset asthma diagnosed in adult age. Respir Med. 2015; 109 (8): 944-54. DOI: 10.1016/j.rmed.2015.05.001.

12. Javed $A$, Yoo $K H$, Agarwal $K$, Jacobson RM, Li X, Juhn YJ, et al. Characteristics of children with asthma who achieved remission of asthma. J Asthma. 2013; 50 (5): 472-9. DOl: 10.3109/02770903.2013.787625.

13. Ignatova GL, Zhorina YV, Abramovskikh OS, Zherebtsova IA. Clinical course and remission rate in adult patients with atopic asthma in Chelyabinsk. Russian Pulmonology. 2019; 29 (3): 263-8. DOI: 10.18093/0869-0189-2019-29-3-263-268. Russian.

14. Global Initiative for asthma - NHLBI/WHO Workshop Report/ National Heart Lung Blood Institute Updated 2016. https:// ginasthma.org/ (дата обращения: 19.09.2018).

15. Chuchalin AG, Aysanov ZR, Chikina SY, Chernyak AV, Kalmanova EN. Federal guidelines of Russian Respiratory Society on spirometry. Russian Pulmonology. 2014; (6): 11-23. Russian.

16. Koh YY, Kang H, Nah KM, Kim CK. Absence of association of peripheral blood eosinophilia or increased eosinophil cationic protein with bronchial hyperresponsiveness during asthma remission. Ann Allergy Asthma Immunol. 2003; 91 (3): 297-302. DOI: 10.1016/S1081-1206(10)63533-8.

17. Karjalainen J, Hulkkonen J, Nieminen MM, Huhtala H, Aromaa A, Klaukka T, et al. Interleukin-10 gene promoter region polymorphism is associated with eosinophil count and circulating immunoglobulin $E$ in adult asthma. Clin Exp Allergy. 2003; 33 (1): 78-83. DOI: 10.1046/j.1365-2222.2003.01577.x 


\section{ORIGINAL RESEARCH I PULMONOLOGY}

18. Huang ZY, Cheng BJ, Wan Y, Zhou C. Meta-analysis of the IL10 promoter polymorphisms and pediatric asthma susceptibility. Genet Mol Res. 2016; 15 (2): gmr.15028320 DOI: 10.4238/ gmr.15028320

19. Nie W, Fang Z, Li B, Xiu QY. Interleukin-10 promoter polymorphisms and asthma risk: a meta-analysis. Cytokine. 2012; 60 (3): 849-55. DOI: 10.1016/j.cyto.2012.08.023.

20. Tang L, Lin HG, Chen BF. Association of IL4 promote polymorphisms with asthma: a meta-analysis. Genet Mol Res. 2014; 13 (1): 1383-94.

21. Heinzmann A, Mao X-Q, Akaiwa M, Kreomer RT, Gao PS, Onshima K, et al. Genetic variants of IL13 signalling and human asthma and atopy. Human Molecular Genetics. 2000; 9 (4): 54959. DOI: $10.1093 / \mathrm{hmg} / 9.4 .549$
22. Liu Z, Li P, Wang J, Fan Q, Yan P, Zhang X, et al. A meta-analysis of IL13 polymorphisms and pediatric asthma risk. Med Sci Monit. 2014; (20): 2617-23. DOI: 10.12659/MSM.891017.

23. Mei Q, Qu J. Interleukin-13 +2044 G/A and $+1923 \mathrm{C} / \mathrm{T}$ polymorphisms are associated with asthma susceptibility in Asians: A meta-analysis. Medicine (Baltimore). 2017; 96 (51): e9203. DOI: 10.1097/MD.0000000000009203.

24. Zheng XY, Guan WJ, Mao C, Chen HF, Ding H, Zheng JP, et al. Interleukin-10 promoter 1082/2819/2592 polymorphisms are associated with asthma susceptibility in Asians and atopic asthma: a meta-analysis. Lung. 2014; 192 (1): 65-73.

25. Guerra S. Clinical remission of asthma: what lies beyond? Thorax. 2005; 60 (1): 5-6. DOI: 10.1136/thx.2004.033480. 